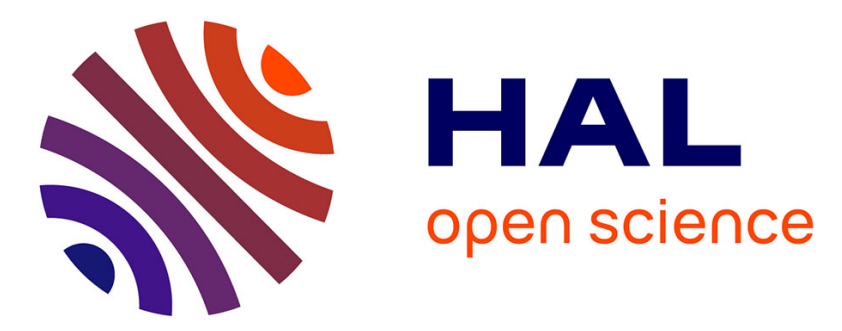

\title{
Chemical segregation and precipitation at anti-phase boundaries in thermoelectric Heusler-Fe2VAl
}

Leonie Gomell, Shyam Katnagallu, Abou Diack-Rasselio, Stefan Maier, Loic Perriere, Christina Scheu, Eric Alleno, Baptiste Gault

\section{- To cite this version:}

Leonie Gomell, Shyam Katnagallu, Abou Diack-Rasselio, Stefan Maier, Loic Perriere, et al.. Chemical segregation and precipitation at anti-phase boundaries in thermoelectric Heusler-Fe2VAl. Scripta Materialia, 2020, 186, pp.370-374. 10.1016/j.scriptamat.2020.04.037 . hal-03051791

\section{HAL Id: hal-03051791 https://hal.science/hal-03051791}

Submitted on 10 Dec 2020

HAL is a multi-disciplinary open access archive for the deposit and dissemination of scientific research documents, whether they are published or not. The documents may come from teaching and research institutions in France or abroad, or from public or private research centers.
L'archive ouverte pluridisciplinaire HAL, est destinée au dépôt et à la diffusion de documents scientifiques de niveau recherche, publiés ou non, émanant des établissements d'enseignement et de recherche français ou étrangers, des laboratoires publics ou privés. 


\title{
Chemical segregation and precipitation at anti-phase boundaries in thermoelectric Heusler-Fe 2 VAl
}

Leonie Gomell ${ }^{1}$, Shyam Katnagallu ${ }^{1, \#}$, Abou Diack Rasselio ${ }^{2}$, Stefan Maier ${ }^{3}$, Loïc Perrière ${ }^{2}$, Christina Scheu ${ }^{1}$, Eric Alleno ${ }^{2}$, Baptiste Gault ${ }^{1,4, *}$

1 Max-Planck-Institut für Eisenforschung, Max-Planck-Str. 1, 40237, Düsseldorf, Germany

2 Univ Paris Est Creteil, CNRS, ICMPE (UMR7182), 2 rue Henri Dunant, F-94320, Thiais, FRANCE

3 Institute of Physics IA, RWTH Aachen University, 52074 Aachen, Germany

4 Department of Materials, Royal School of Mines, Imperial College London, London, UK

\#, now at Institute of Nanotechnology, Karlsruhe institut für technologie, Hermann-vonHelmholtzplatz 1, 76344, Eggenstien-Leopoldshafen, Germany

; * corresponding author: b.gault@mpie.de

\begin{abstract}
$\mathrm{Fe}_{2} \mathrm{VAl}$ exhibits promising properties for thermoelectric applications. Here, we investigated the microstructure of melt spun $\mathrm{Fe}_{2} \mathrm{VAl}$ using electron microscopy, atom probe tomography and field ion microscopy. We observe platelet-shaped $\mathrm{VC}_{\mathrm{x}} \mathrm{N}_{\mathrm{y}}$ precipitates in the vicinity of antiphase boundaries (APB) oriented along the $\{010\}$-plane. The mean distance between these precipitates is $(140 \pm 40) \mathrm{nm}$. This distance is shorter than the mean free phonon path at room temperature in $\mathrm{Fe}_{2} \mathrm{VAl}$, thus, these $\mathrm{VC}_{\mathrm{x}} \mathrm{N}_{\mathrm{y}}$ precipitates, combined with the APB may efficiently lower the thermal conductivity of the alloy.
\end{abstract}


The necessity for generating low-carbon energy has led to extensive research in the field of thermoelectric (TE) materials in recent years. TE devices can directly transform waste heat into usable energy, are silent, scalable, and barely require any maintenance [1]. However, TE generators are still primarily used in niche applications, e.g. remote power supplies, such as in deep-space missions [2], where no other energy generation methods are available. Other possible applications such as automotive TE generators or solar thermal power generation are conceivable, but technological hurdles need to be overcome [3]. State-of-the-art TE materials such as Skutterudites [4], $\mathrm{Bi}_{2} \mathrm{Te}_{3}$ [5], $\mathrm{Sb}_{2} \mathrm{Te}_{3}$ [6], or TAGS [7] show good TE properties, but are expensive and toxic, hindering their wider applicability.

Alternative TE materials must be developed for a cost-effective, non-toxic, and scalable energy production. A promising material, which displays a good power factor $\left(>5 \mathrm{~mW} \mathrm{~m}^{-1} \mathrm{~K}^{-2}\right.$ at $\left.300 \mathrm{~K}\right)$, is the Heusler compound $\mathrm{Fe}_{2} \mathrm{VAl}$ [8]. $\mathrm{Fe}_{2} \mathrm{VAl}$ is highly durable [9] and contains earth-abundant elements. It is a semimetal with a sharp pseudogap, which is favorable for TE applications [10,11]. Although the power factor is high, its high thermal conductivity $(\kappa)$ is the major limiting factor in its TE performances [8]. Different routes to enhance phonon scattering and decrease $\kappa$ have been investigated, such as doping [10,12-14], off-stoichiometry [15,16], introduction of defects and exploiting disorder in the structure [17-20].

Another, not as widely studied way of introducing phonon scattering centers is to introduce interfaces, and in particular antiphase boundaries (APB). APBs can be generated inside the L 21 Heusler phase by fast quenching from high temperatures, where $\mathrm{Fe}_{2} \mathrm{VAl}$ is stable in two variants: partly disordered B2 and fully disordered A2, as described by Maier et al. [19]. A method for achieving the necessary high cooling rates is melt spinning, where the melt is dropped onto a cooled, rotating metallic wheel and leading to rapidly quenched flakes of the material. A schematic of two antiphase domains (APD) in the L2 1 phase separated by an APB is visualized in the supplementary figure S1a. The APDs can be converted into each other by a $\{100\}_{\mathrm{B} 2}$ translation, which exists in the disordered B2 structure but is missing in the ordered $\mathrm{L} 2{ }_{1}$ structure [21]. Another possible interface (Fig. S1b) is a coherent order-disorder boundary. The ordered L2 1 phase and disordered $\mathrm{B} 2$ or $\mathrm{A} 2$ phase are coexisting without a change in the crystallographic orientation.

Here, we show evidence for segregation and precipitation in the bulk and at interfaces in melt spun $\mathrm{Fe}_{2} \mathrm{VAl}$. We cannot differentiate specifically between different coherent interfaces, and for readability, boundaries observed and discussed herein will be referred to as APBs. Using scanning 
electron microscopy (SEM), atom probe tomography (APT) and field ion microscopy (FIM), we report on vanadium carbides and vanadium nitrides at APBs. These could act as phonon scattering centers and hence open opportunities for further microstructural adjustments for lowering the thermal conductivity.

Stoichiometric $\mathrm{Fe}_{2} \mathrm{VAl}$ was synthesized by melt spinning. The pure elements Fe (Strem Chemicals, $99.95 \%), \mathrm{V}$ (Chempur, 99.9\%), and Al (Alfa Aesar, 99.9965\%) were melted together and subsequently ejected at $1490{ }^{\circ} \mathrm{C}$ onto a water-cooled, rotating $\mathrm{CuCoBe}$ wheel spinning at $24.5 \mathrm{~m} / \mathrm{s}$, ensuring a fast quenching rate. This process leads to approximately $20 \mu \mathrm{m}$ thick flakes. Inductively Coupled Plasma Optical Emission Spectrometry determined the average chemical composition to be $\mathrm{Fe}_{50.54} \mathrm{~V}_{24.81} \mathrm{Al}_{24.65}$ (at.\%). X-ray diffraction (XRD) indicates the presents of the $\mathrm{L} 2{ }_{1}$ ordered phase (Fig. S2). However, the co-existence of B2 and A2 phase cannot be excluded from the XRD pattern.

Microscale analyses of the microstructure were performed using scanning electron microscopy (SEM) and energy-dispersive X-ray spectroscopy (EDX) using a Zeiss 1540 XB SEM. The samples were analyzed as-cast without any polishing, and after hand grinding to observe the microstructure on the surface and inside the sample. The sample was initially prepared using SiC papers and final polishing was done using a colloidal silica suspension $(0.25 \mu \mathrm{m})$ in a vibrating polishing machine (Buehler Vibromet 2).

Near-atomic scale investigations were performed using field ion microscopy (FIM) and atom probe tomography (APT). Needle-shaped specimens for APT and FIM were prepared using a dual-beam focused-ion-beam (FIB) instrument (FEI Helios Nanolab600i) with a Ga ion source or an FEI Helios Plasma-FIB with a Xe-plasma ion source by an in-situ lift-out method and a subsequent sharpening process [22]. For correlative FIM/APT analysis, a LEAPTM 5000 XS (Cameca Instruments) was used. APT was conducted in voltage pulsing mode using a pulse repetition rate of $125 \mathrm{kHz}$ and a pulse fraction of $15 \%$. For FIM, Ne was used as an imaging gas to image the sample surface at $50 \mathrm{~K}$. The $\mathrm{Ne}$ gas pressure while imaging was kept at $1 \cdot 10^{-7} \mathrm{mbar}$ and, when possible, images were acquired at the best imaging voltage. APT measurements were also performed on a LEAPTM 5000 XR (Cameca Instruments) in laser-pulsing mode. The laser power was set to $25 \mathrm{pJ}$ and the repetition rate was $250 \mathrm{kHz}$. For both APT measurements, the base temperature of the specimen was kept at $60 \mathrm{~K}$ and a target detection rate was set to $0.5 \%$. The IVAS 3.8.4 software and MATLAB 2017a were used for data reconstruction and analysis. 
Fig. 1 presents backscattered electron (BSE) and secondary electron (SE) micrographs of the unpolished and mechanically polished samples as well as a cross sectional image. Parallel to the surface (Fig. 1a), the BSE image shows two layers of grains. The mean size of the small surface grains (Fig 1a, (1)) is $(1.7 \pm 0.1) \mu \mathrm{m}$ whereas the regular grain size within the flake is $(5.5 \pm 0.4)$ $\mu \mathrm{m}$ (Fig 1a, (2)). The SEM image used for the analysis of the mean grain sizes is shown in the supplemental data Fig. S3. Both layers are visible due to the interaction volume of the electron beam and the material, which is in the order of $1 \mu \mathrm{m}$ for an acceleration voltage of $15 \mathrm{kV}$ and therefore can penetrate the flake deeper than the mean thickness of the surface grains. Fig. 1b shows a polished surface, where only the regular grains are observed as the surface layer is polished away. The small surface grains can also be seen in Fig. 1c on the edge of the flake (4), where they are observed from the surface (3) and the cross section (5).
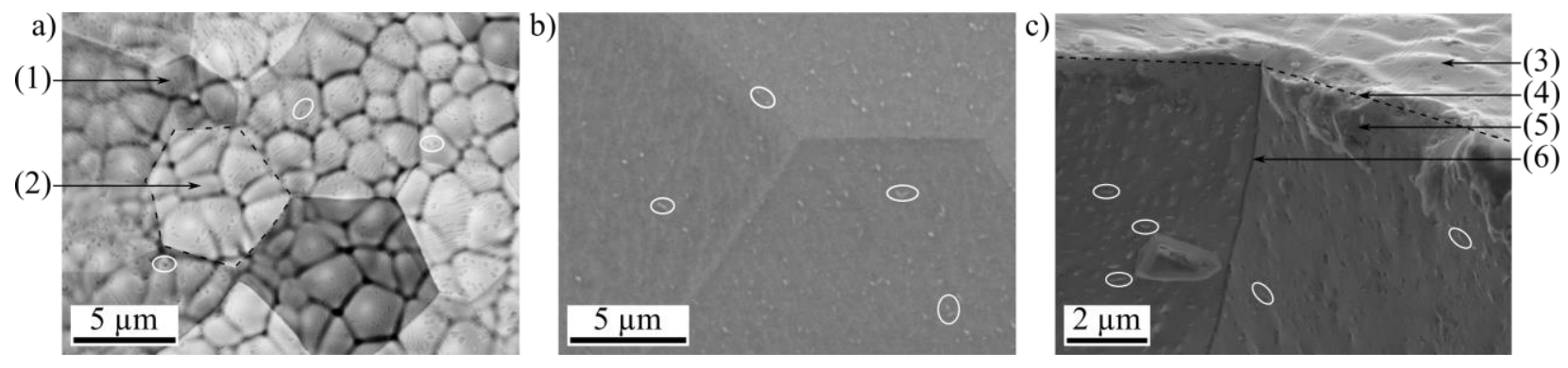

Fig. 1. SEM images of melt spun Fe2VAl. The white circles indicate exemplary positions where platelet-shaped precipitates are observed. (a) BSE image of unpolished melt spun flakes (1) small surface grains (2) regular grains. (b) SE image of the polished sample, showing the regular grains and precipitates within the flake, (c) Cross section view along the edge of an unpolished sample. (3): surface grains observed from the surface of the flake, (4) edge of the sample, indicated by the dashed line, (5) surface grains layer observed from the cross section, (6) grain boundary of lower lying regular grains.

All SEM images show platelet-like precipitates, not only at the grain boundaries but also inside the grains. These precipitates are highlighted by white circles. The precipitates within one grain are oriented either parallel or perpendicular to each other (Fig 1a, c), but their orientation differs between grains (Fig 1a). This indicates that the orientation of the precipitates is dependent on the crystallographic orientation of the grains. The $90^{\circ}$ angle between precipitates within one grain (Fig 1c) could indicate that the precipitates are on (100) planes. The average size of these precipitates is $120 \times 40 \mathrm{~nm}^{2}$ and they are separated by a mean distance of $(140 \pm 40) \mathrm{nm}$.

APT and FIM are used to confirm the presence of ordered phases and antiphase boundaries while analyzing the elemental distribution at the near-atomic scale. A field-ion micrograph is displayed 
in Fig. 2a. It shows two ordered domains separated bright-imaging feature and indicated by black arrows. The ordering of the right domain is revealed for instance by the relative contrast at the (111)-pole [23]. It consists of rings with alternating intensities, indicating planes with different atomic occupancies. This is true for the L2 1 phase, where a $\{111\}$ plane, occupied by Fe atoms, sandwiches alternating $\mathrm{Al}$ and $\mathrm{V}$ planes, as visualized in Fig. 2b. The B2 phase consists of $\{111\}$ planes occupied by Fe, followed by planes with a mixed occupancy of Al and V. Thus, only the A2 phase can be excluded from this FIM micrograph. The rings formed by $\{110\}$ planes do not show any alternating intensity, as the planes are occupied with Fe, V, and Al, even in L $2{ }_{1}$ ordering. The other domain on the left part of the micrograph shows the (100) pole. Ordering on that pole cannot be directly observed because of the small interplanar distance and associated limited resolution. The two domains appear coherent, as evidenced by the pattern continuity at the (101) pole across the interface. The contrast of the interface indicates that it is decorated by high-evaporation field elements. This coherent boundary is likely a typical APB (Fig. S1a) or an interface between an ordered and a disorder region (Fig. S1b).

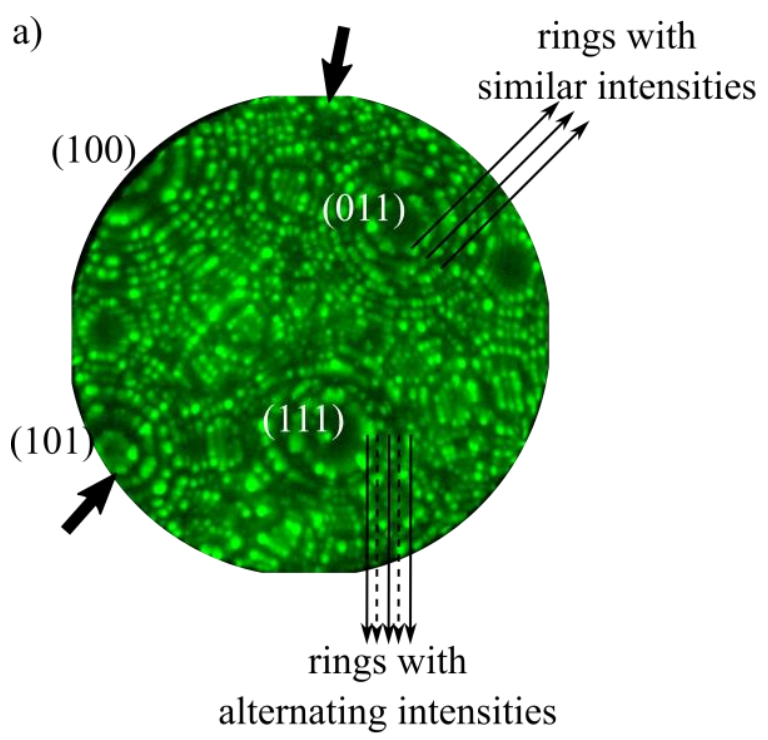

$\{011\}$

$\{111\}$

alternating intensities b) top view

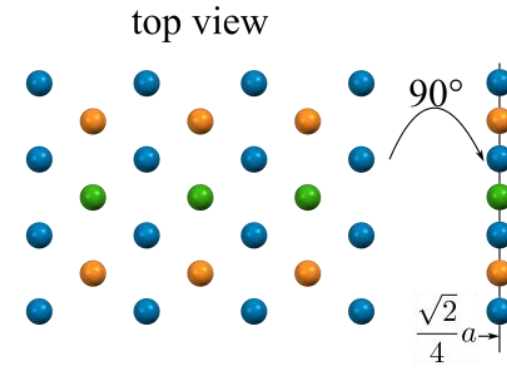

side view
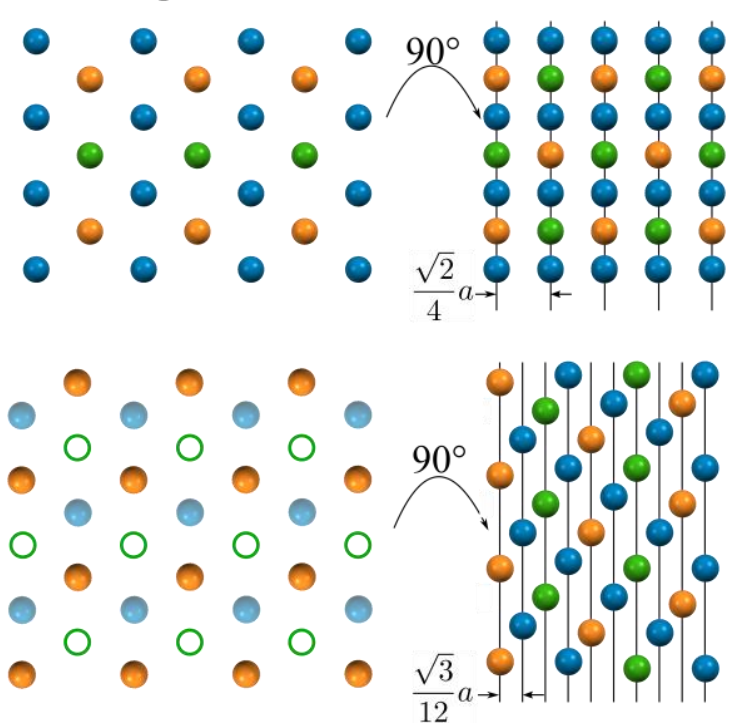

Fig. 2. a) FIM micrograph showing two domains separated by a coherent boundary. The boundary is marked by the arrows. The (111) pole shows rings with alternating intensities due to an ordering of the (111) lattice planes. (b) Visualization of the $\{011\}$ and $\{111\}$ planes of the L2 1 phase. Fe, V, and Al are symbolized by blue, green, and orange spheres, respectively. The $\{011\}$ plane shows a mixed coverage on parallel planes. On $\{111\}$ planes, a plane occupied by $\mathrm{Al}$ is followed by a Fe-plane (half-transparent spheres), which is followed by a V-plane (green circles). The side view is rotated by $90^{\circ}$ with regards to the top view, showing the crystallographic sequence of the corresponding planes, which are indicated by the black lines. 
Correlative APT and FIM is shown in Fig. 3: FIM was performed before and after APT as indicated by the light blue and dark blue circles, respectively. During the APT measurement, approximately 56.7 million ions were detected and the analysis was stopped when a strong planar segregation appeared. The specimen fractured before FIM could be performed in the best imaging conditions, yet poles observed in both FIM micrographs are at the same positions, and can be indexed according to their Miller indices (Fig. 3a). The (111) pole, exhibiting a 3-fold symmetry, is observed near the center. The planar feature seen in APT appears as a brightly-imaging feature across the field-of-view in the second FIM image. The poles on either side of this feature seem to be at the same position, which indicates no change in the crystallographic orientation across this interface, which reinforces the likelihood that this is an APB. The crystallographic orientation of the APB can be observed in the AP reconstruction. A desorption map before and at the APB is shown next to the reconstruction (Fig. 3b). The different poles can be indexed similarly to the FIM micrographs. Within the vicinity of the poles, the crystallographic planes can be indexed [24], which allows us to determine that this APB lies on the $(010)$ planes.

The AP reconstruction of a small region across the boundary shows (011) planes on either side of the boundary (Fig. 3d). The angle between the APB, visualized by the iso-composition interface, and the planes is approximately $45^{\circ}$, which supports the (010)-orientation of the APB. The spatial distribution map, visualizing the distance of the planes on either side of the boundary is given in the supplemental figure Fig. S4. This further indicates that same sets of planes are imaged on either side of the APB as their separation is similar.

As shown in Fig. S1 an APB can exist without any change in the chemical composition. However, similar to grain boundaries, an energetically driving force for segregation exists at an APB and was analyzed theoretically for $\mathrm{Fe}_{3} \mathrm{Al}$ [21]. The APB appears to the segregated to a point where they can trigger precipitation of $\mathrm{VC}_{\mathrm{x}} \mathrm{N}_{\mathrm{y}}$. Here, we observe coherent precipitation of $\mathrm{V}, \mathrm{C}$, and $\mathrm{N}$ in the form of $\mathrm{VC}_{\mathrm{x}} \mathrm{N}_{\mathrm{y}}$, as evidenced by the iso-composition interface in the AP reconstruction (Fig. $3 \mathrm{c}$ ). The iso-composition interface marks regions with a concentration of $\mathrm{C}, \mathrm{N}, \mathrm{VC}$, and $\mathrm{VN}$-ions of at least 3 at.\%. Within the matrix, a smaller spherical $\mathrm{VN}_{\mathrm{y}}$ precipitate is found, which is also shown by the iso-composition interface. 

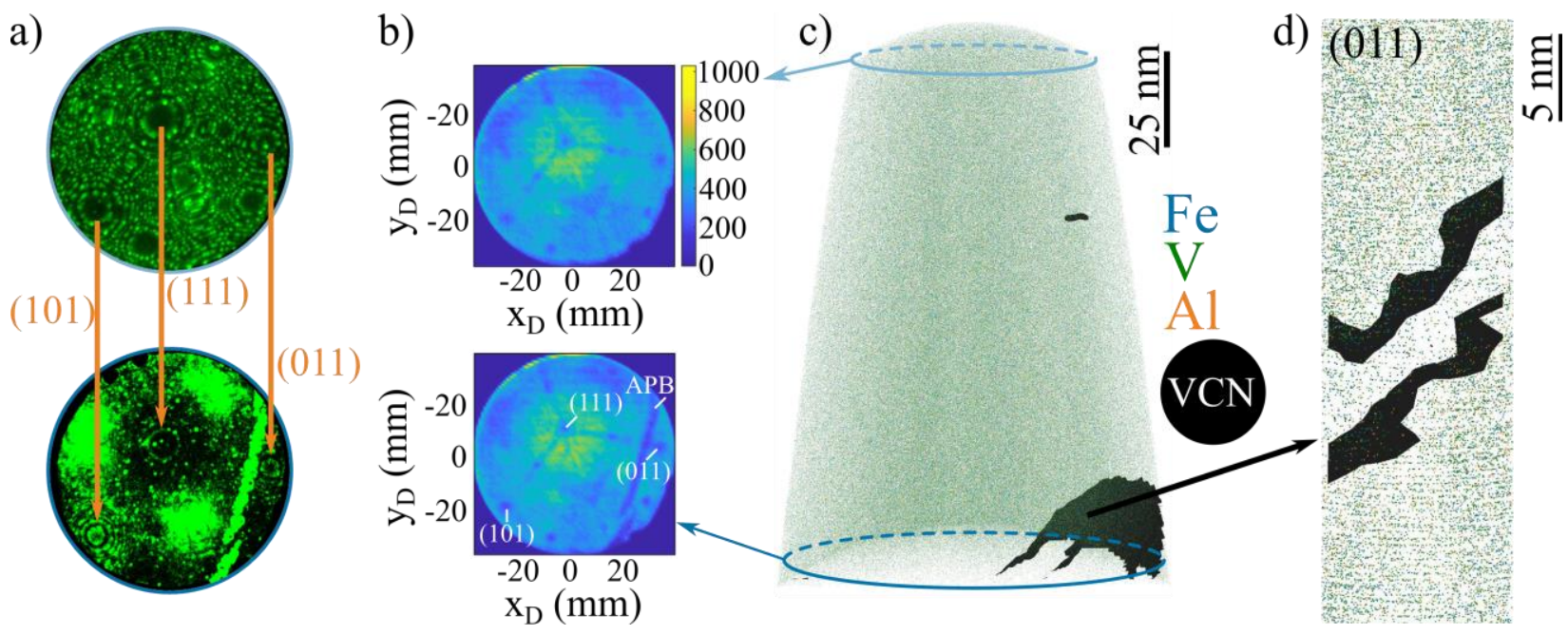

Fig. 3. Correlative APT and FIM study. a) FIM micrographs, conducted before and after the APT run, as indicated by the blue circles. The arrows mark the poles visible in both FIM images, which show no change in the crystallographic orientation on either side of the precipitate indicating an antiphase boundary. b) AP desorption maps, showing the same poles as the FIM micrographs. c) AP reconstruction showing the elemental distribution of Fe, $V$, and Al ions and an iso-composition interface with 3 at.\% $V C_{x} N_{y}$ as labeled next to the reconstructed data. The iso-composition interface shows a platelet-shaped $V C_{x} N_{y}$ precipitate at the antiphase-boundary and a smaller $V N_{y}$ precipitate within the matrix. d) AP reconstruction of (011) planes around the APB. On either side of the APB, the parallel planes are observed.

A closer look at an APB in another dataset is shown in Fig. 4. A set of iso-composition surfaces, with the same threshold as in Fig. 3, highlights two larger and a smaller platelet-shape precipitates (Fig. 4c). The density map on either side of the APB shows a continuity of the position of the (100) pole (Fig. 4a). Within a region-of-interest close to the pole, the planes and the APB appear parallel, as shown in Fig. 4b, confirming that the APB lies on the (100) planes. A composition profile was calculated along a $20 \mathrm{~nm}$-diameter cylindrical region-of-interest with a step size of $0.3 \mathrm{~nm}$ (Fig. 4d). On either side of the APB, the composition is near-stoichiometric. In the vicinity of the APB, highlighted by the gray box, an enrichment of V, C, and $\mathrm{N}$ is observed, and its composition is (63.2 $\pm 1.7)$ at. $\% \mathrm{~V},(13.5 \pm 1.1)$ at. $\% \mathrm{~N},(9.6 \pm 0.9)$ at. $\% \mathrm{C},(8.2 \pm 0.8)$ at. $\% \mathrm{Fe}$, and $(5.3 \pm 0.7)$ at. $\% \mathrm{Al}$. These suggest precipitates with a stoichiometry close to $(\mathrm{V}, \mathrm{Fe}, \mathrm{Al})_{3}(\mathrm{C}, \mathrm{N})$. Along the $\mathrm{APB}$, outside of the precipitate, the concentration of $\mathrm{C}$ and $\mathrm{N}$ is small with $(0.10 \pm 0.02)$ at. $\%$ and $(0.08 \pm 0.01)$ at. $\%$, respectively. 
a)

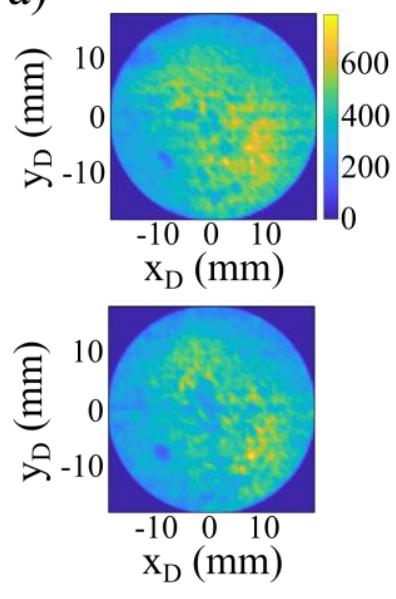

b)

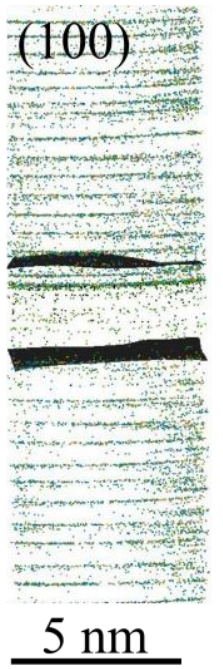

c)
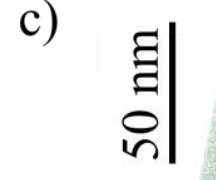

d)
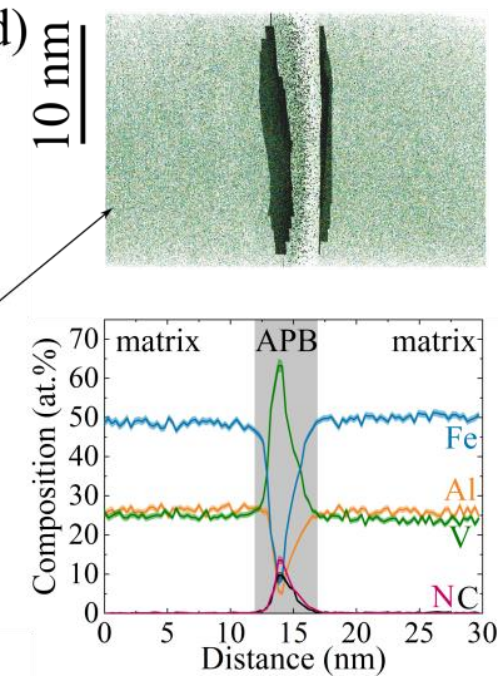

Fig. 4. AP reconstruction of a second specimen. a) The desorption map shows the (100) pole before and after the APB. b) reconstruction of (100) planes around the APB. On either side of the APB, the parallel planes are observed. c) full reconstructed volume, showing the elemental distribution of $\mathrm{Fe}, \mathrm{V}$, and Al ions and an iso-composition interface with 3 at.\% VVC $N_{y}$ as labeled next to the reconstructed data. A platelet-shaped precipitate is observed at an APB. d) elemental distribution, calculated in a cylindrical region of interest with a diameter of $20 \mathrm{~nm}$ and a step size of $3 \mathrm{~nm}$ and is shown as a concentration plot. An enrichment of $V, N, C$ was found at the APB.

Here, carbon and nitrogen were not intentionally added to the material. However, both elements are common impurities in commercial vanadium and iron pellets and may originate from the atmosphere during the processing. Due to the high affinity of vanadium to carbon, it can form carbides at temperatures of $800-1000{ }^{\circ} \mathrm{C}$ during the melt spinning process. It can also react with nitrogen at temperatures above $800{ }^{\circ} \mathrm{C}[25]$. The tendency for segregation can be related to the relatively high $\mathrm{APB}$ energy of $\mathrm{Fe}_{2} \mathrm{VAl}$ is $0.27 \pm 0.04 \mathrm{~J} / \mathrm{m}^{2}$ for a $\left(\frac{a}{2}\right)\langle 1 \overline{11\rangle}(01 \overline{1})$ APB [26], compared to e.g. $0.08 \pm 0.025 \mathrm{~J} / \mathrm{m}^{2}$ for $\mathrm{Fe}_{3} \mathrm{Al}$ [27]. The high APB energy can act as a driving force for a segregation, as segregation to APB can reduce its energy [28,29]. It was shown, that $\mathrm{Cr}$ segregation to $\mathrm{APBs}$ in $\mathrm{Fe}_{3} \mathrm{Al}$ can either reduce or enhance the APB energy, depending on the position of the impurities within the matrix [27]. The locally higher composition in V, C, N can help trigger further precipitation [30]. For $\mathrm{Fe}_{3} \mathrm{Al}$, Koizumi et al. [31] described a stabilization of APBs due to segregation of solute atoms and vacancies.

The high affinity of vanadium to form carbides and nitrides offers opportunities to intentionally add $\mathrm{C}$ and $\mathrm{N}$ and trigger additional precipitation. Carbides and nitrides might further increase phonon scattering and have interesting effects on the transport properties of the material. This combination of nanoprecipitates and APBs should reduce the thermal conductivity. To have a 
significant influence, the mean phonon free path needs to be longer than the mean distance of the precipitates. For $\mathrm{Fe}_{2} \mathrm{VAl}$ at room temperature, the mean free phonon path was estimated to be 2.4 $\mu \mathrm{m}$. The mean distance $\sim 140 \mathrm{~nm}$ of the platelet-shaped precipitates could be observed in the mesoscale SEM images and is smaller than the phonon mean free path. Additionally, the plateletshaped precipitates located at APBs, which give rise to another phonon scattering center. The experimental investigation and calculation of the thermoelectric properties of $\mathrm{Fe}_{2} \mathrm{VAl}$, considering the $\mathrm{APB}$ and $\mathrm{VC}_{\mathrm{x}} \mathrm{N}_{\mathrm{y}}$ precipitates, are presently beyond the scope of this paper. Nonetheless, they will be part of future work.

To summarize, we investigated the microstructure of $\mathrm{Fe}_{2} \mathrm{VAl}$, synthesized via melt spinning. We performed microstructural observations using electron microscopy and investigated the composition of APBs and precipitates at the near-atomic level using atom probe tomography. This approach allows us to gain information on different hierarchical length scales. SEM observations were used to determine the statistical distribution of precipitates and their size on the microscale. Platelet-shaped precipitates are found, separated on average by $(140 \pm 40) \mathrm{nm}$. APT reveals the chemistry of the platelet-shaped precipitates to be $\mathrm{VC}_{\mathrm{x}} \mathrm{N}_{\mathrm{y}}$. These precipitates appear at APBs oriented along the $\langle 100\rangle$ direction, as indicated by APT and FIM measurements. APBs are stabilized in the $\mathrm{L} 2{ }_{1}$ phase due to the fast quenching from the disordered $\mathrm{B} 2$ and $\mathrm{A} 2$ phase, in which $\mathrm{Fe}_{2} \mathrm{VAl}$ is stable at temperatures higher than $1080{ }^{\circ} \mathrm{C}$ and $1190{ }^{\circ} \mathrm{C}$, respectively [19]. The APBs and corresponding precipitates may act as phonon scattering centers and lower the thermal conductivity, leading to an improvement of the thermoelectric properties. 


\section{References}

[1] G.J. Snyder, E.S. Toberer, Nat. Mater. 7 (2008) 105-14.

[2] L. Yang, Z.G. Chen, M.S. Dargusch, J. Zou, Adv. Energy Mater. 8 (2018) 1-28.

[3] J. Yang, T. Caillat, MRS Bull. 31 (2006) 224-229.

[4] C.S.R. Matthes, D.F. Woerner, T. Caillat, S. Pinkowski, IEEE Aerosp. Conf. Proc. 2019March (2019) 1-9.

[5] H. Mamur, M.R.A. Bhuiyan, F. Korkmaz, M. Nil, Renew. Sustain. Energy Rev. 82 (2018) 4159-4169.

[6] T. Thonhauser, J. Scheidemantel, O. Sofo, V. Badding, D. Mahan, Phys. Rev. B - Condens. Matter Mater. Phys. 68 (2003) 1-8.

[7] E.M. Levin, S.L. Bud'Ko, K. Schmidt-Rohr, Adv. Funct. Mater. 22 (2012) 2766-2774.

[8] E. Alleno, Metals (Basel). 8 (2018) 864.

[9] M. Mikami, T. Kamiya, K. Kobayashi, Thin Solid Films 518 (2010) 2796-2800.

[10] H. Al-Yamani, B. Hamad, J. Electron. Mater. 45 (2016) 1101-1114.

[11] I. Knapp, B. Budinska, D. Milosavljevic, P. Heinrich, S. Khmelevskyi, R. Moser, R. Podloucky, P. Prenninger, E. Bauer, Phys. Rev. B 96 (2017) 045204.

[12] W. Lu, W. Zhang, L. Chen, J. Alloys Compd. 484 (2009) 812-815.

[13] M. Mikami, K. Kobayashi, J. Alloys Compd. 466 (2008) 530-534.

[14] K. Renard, A. Mori, Y. Yamada, S. Tanaka, H. Miyazaki, Y. Nishino, J. Appl. Phys. 115 (2014).

[15] H. Miyazaki, S. Tanaka, N. Ide, K. Soda, Y. Nishino, Mater. Res. Express 1 (2014).

[16] Y. Nishino, H. Kato, M. Kato, U. Mizutani, Phys. Rev. B - Condens. Matter Mater. Phys. 63 (2001) 3-6.

[17] S. Bandaru, A. Katre, J. Carrete, N. Mingo, P. Jund, Nanoscale Microscale Thermophys. Eng. 21 (2017) 237-246. 
[18] D.I. Bilc, P. Ghosez, Phys. Rev. B - Condens. Matter Mater. Phys. 83 (2011) 1-6.

[19] S. Maier, S. Denis, S. Adam, J.C. Crivello, J.M. Joubert, E. Alleno, Acta Mater. 121 (2016) $126-136$.

[20] C. Venkatesh, V. Srinivas, V. V. Rao, S.K. Srivastava, P. Sudheer Babu, J. Alloys Compd. 577 (2013) 417-425.

[21] H. Wondratschek, W. Jeitschko, Acta Crystallogr. 32 (1976) 664-666.

[22] K. Thompson, D. Lawrence, D.J. Larson, J.D. Olson, T.F. Kelly, B. Gorman, Ultramicroscopy 107 (2007) 131-139.

[23] X.J. Ge, N.X. Chen, W.Q. Zhang, F.W. Zhu, J. Appl. Phys. 85 (1999) 3488-3493.

[24] B. Gault, M.P. Moody, J.M. Cairney, S.P. Ringer, Atom Probe Microscopy, Springer Series in Material Science, New York, 2012.

[25] G. Bauer, V. Güther, H. Hess, A. Otto, O. Roidl, H. Roller, S. Sattelberger, S. Köther-Becker, T. Beyer, Ullmann's Encycl. Ind. Chem. (2016).

[26] P.A. Ferreirós, P.R. Alonso, G.H. Rubiolo, Mater. Sci. Eng. A 684 (2017) 394-405.

[27] M. Friák, M. Všianská, M. Šob, Materials (Basel). 12 (2019) 1-15.

[28] S.K. Makineni, M. Lenz, S. Neumeier, E. Spiecker, D. Raabe, B. Gault, Scr. Mater. 157 (2018) 62-66.

[29] R. Kikuchi, J.W. Cahn, Acta Metall. 27 (1979) 1337-1353.

[30] P.R. Swann, Philos. Mag. 14 (1966) 461-471.

[31] Y. Koizumi, S.M. Allen, Y. Minamino, Acta Mater. 57 (2009) 3039-3051.

[32] C.F. Macrae, I. Sovago, S.J. Cottrell, P.T.A. Galek, P. McCabe, E. Pidcock, M. Platings, G.P. Shields, J.S. Stevens, M. Towler, P.A. Wood, J. Appl. Crystallogr. 53 (2020) 226-235. 
a)

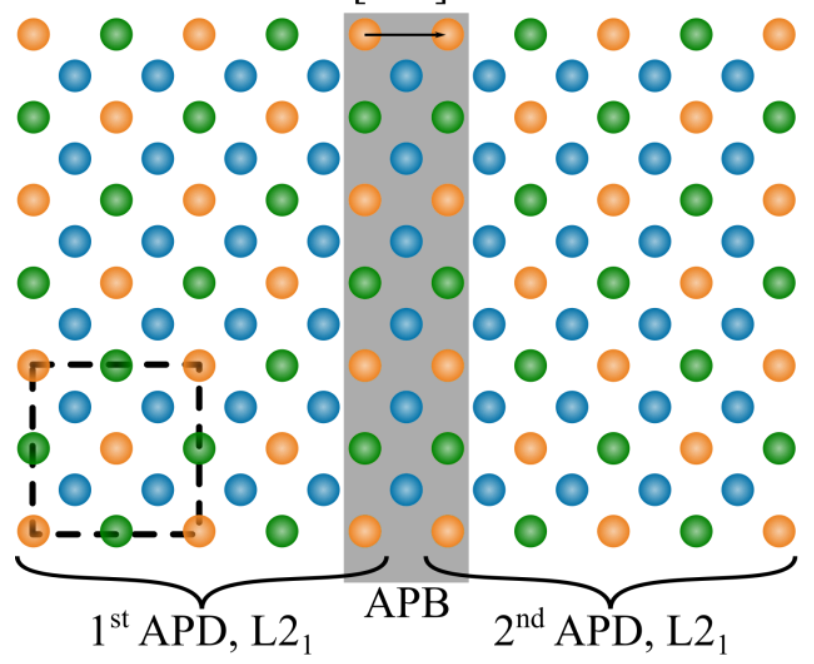

b)

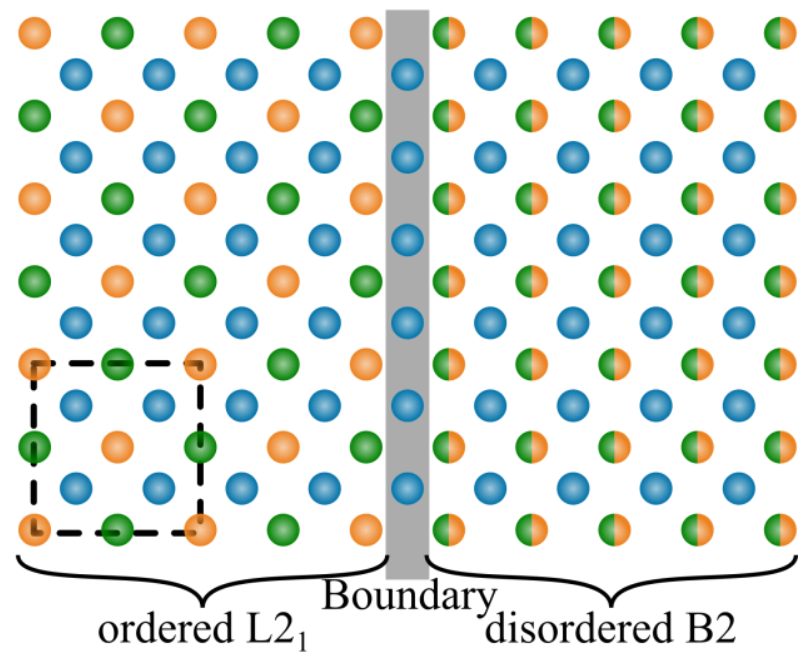

Fig. S1. Schematic representation of boundaries in Fe2VAl. The crystal structure is projected on the (001) plane. The orange, blue, and green spheres represent the Al, Fe, and V atoms, respectively. Mix spheres symbolize atomic positions with a random distribution of the corresponding atoms. The dashed square indicates a unit cell of $\mathrm{Fe}_{2} \mathrm{VAl}$, the grey bar marks the boundary. a) two Heusler (L2 $\left.{ }_{1}\right)$ antiphase domains separated by an $A P B$. The $\{100\}_{B 2}$ translation, which exists in the disordered B2 structure and which is missing in the ordered L2 $2_{1}$ structure, binds the two APDs [21] and is visualized by the arrow. b) orderdisorder boundary between an ordered L21 phase and the partly disordered B2 phase. The fully disordered A2 phase is not shown, but the kind of boundary is similar. 

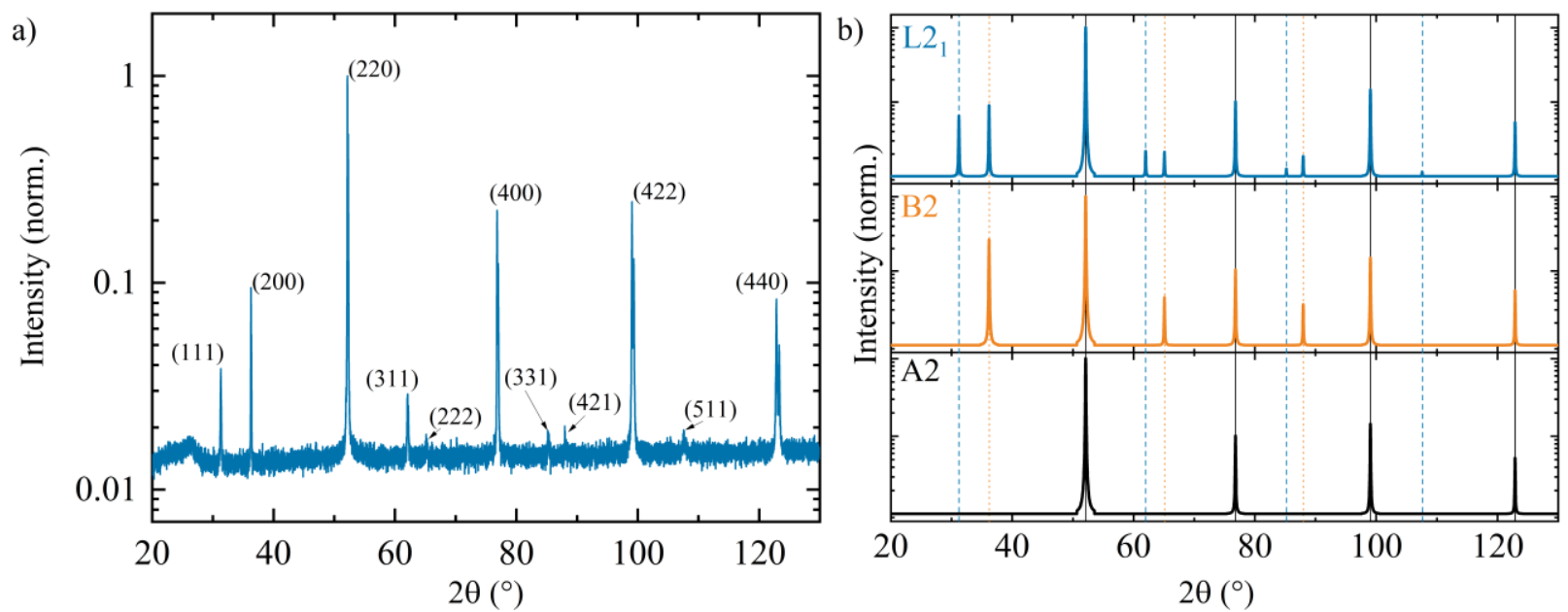

Fig S2. a) XRD pattern collected from the flakes without polishing. A D8 Advance A25-X1 diffractometer equipped with a cobalt x-ray source was used. X'Pert HighScore was used to determine the phase to be L2 ${ }_{1}$. The peaks are indexed according to their Miller indices. b) calculated powder pattern for the L2 $2_{1}$ (ordered), B2 (partly disordered), and A2 (fully disordered) phases of $\mathrm{Fe}_{2} V A l$. The peaks, which only exist in the L2 ${ }_{1}$ phase are marked with blue dashed lines, peaks, which are visible in B2 and L2 ${ }_{1}$ are marked with the orange dotted line, and peaks, observed in all three pattern, are marked with a black line. The calculations of the powder pattern were made using Mercury [32]. The visibility of the peaks (111), (311), (331), (511) reveals the existence of the L2 ${ }_{1}$ phase. However, it cannot be excluded that B2 and A2 phases are coexisting, as the measured XRD pattern is not a powder pattern and, thus, a texture is observed due to the small amount of illuminated grains. Therefore, the intensity relation between the different peaks cannot be used for a calculation of the amount of different phases. This is easiest visible in the comparison of the intensity ratio of peaks (200)/(111) and (222)/(311). The high intensity of (200) compared to (111) could lead to the assumption that a significant amount of B2 phase is existing. In this case, however, the (222) peak would be more intense than the (311) peak, which is not observed. 


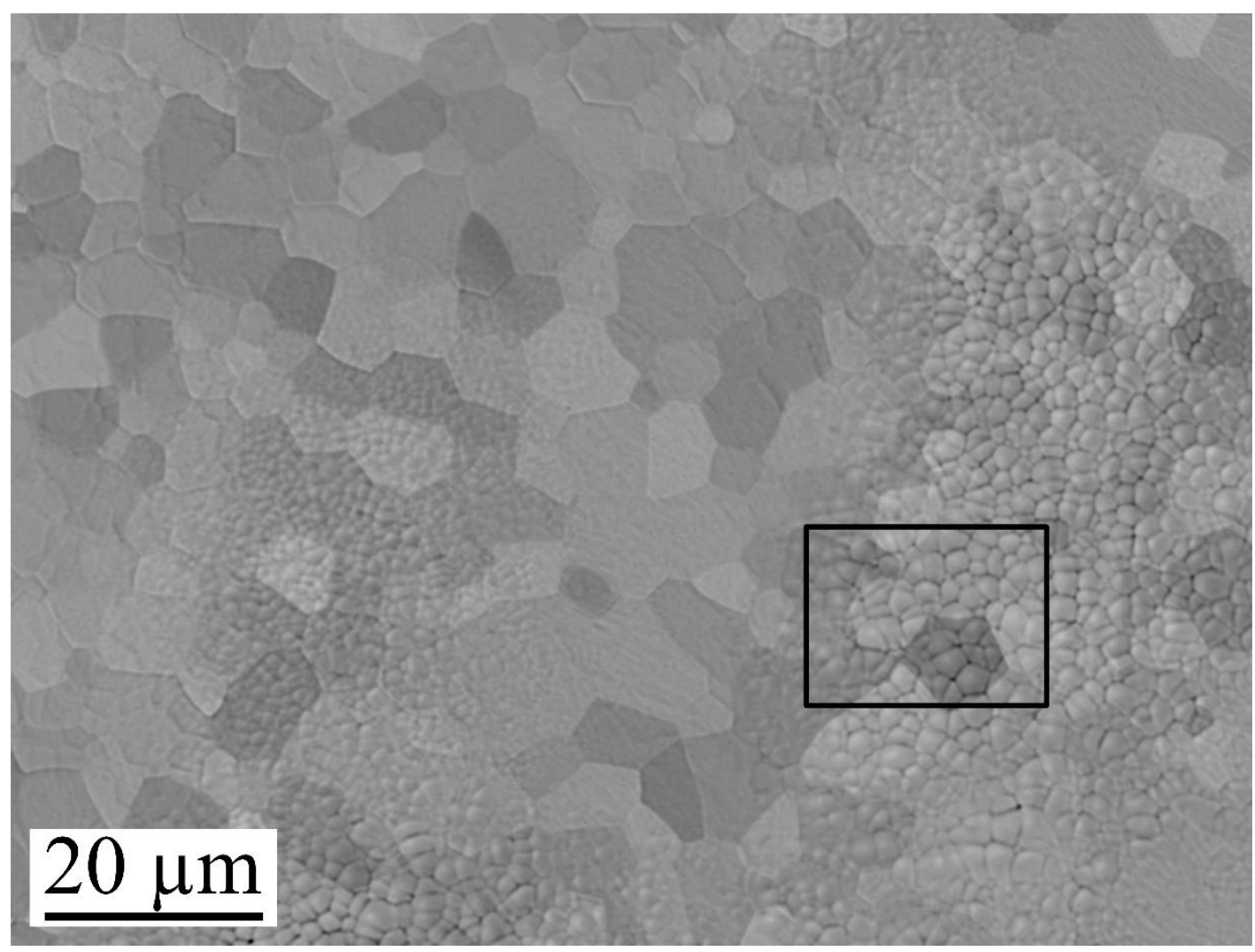

Fig S3. SEM image of the microstructure of unpolished melt spun flakes, conducted with an acceleration voltage of $15 \mathrm{kV}$, used for the determination of the mean grain size. The mean grain size of the larger grains was (5.5 \pm 0.4$) \mu m$ and of the smaller "floating" grains is (1.7 \pm 0.1$) \mu m$. The marked area is the area shown in Fig. 1a. 

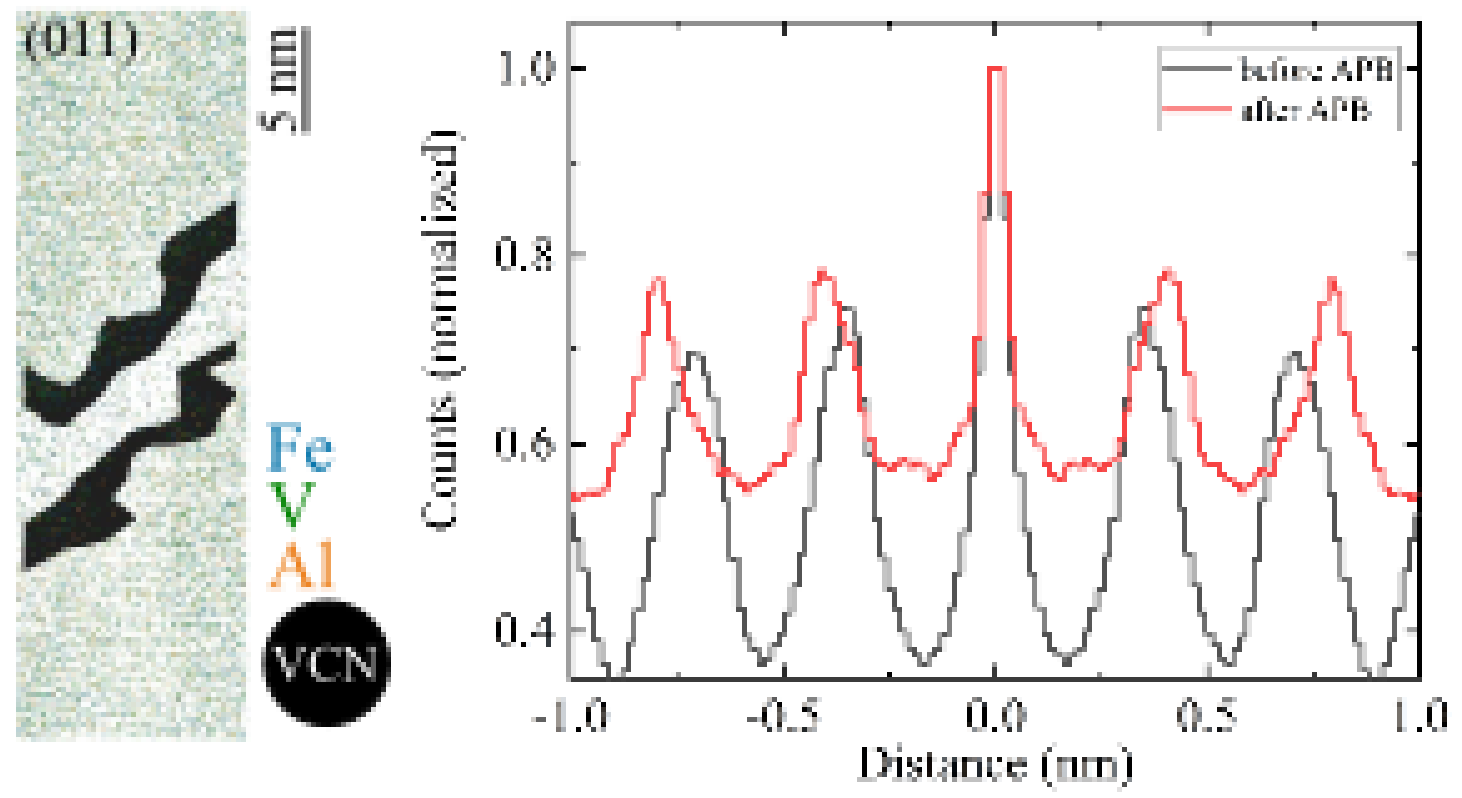

Fig S4. APT reconstruction at (011) pole around APB and spatial distribution map of all detected ions before and after the APB, showing approximately the same distance of the planes. This indicates that the same planes are observed on either side of the boundary, pointing to an APB. 